\title{
Diabetic mastopathy: report of two cases and literature review
}

\author{
Lilian Navarro-Garcia' ${ }^{1 *}$, Miriam Escamilla-Lopez ${ }^{2}$, Ariana Najera-Flores ${ }^{1}$, Fredy Chable-Montero ${ }^{3}$, \\ Ruben Cortes ${ }^{2}$ and Daniel Motola-Kuba ${ }^{1,2}$ \\ ${ }^{1}$ Department of Breast Cancer Radiology; ${ }^{2}$ Oncology Center; ${ }^{3}$ Department of Anatomic Pathology. Medica Sur Hospital, Mexico City, Mexico
}

\begin{abstract}
Introduction: Diabetic mastopathy (DM) is an uncommon, benign entity of self-limiting fibro inflammatory breast disease. It is associated with type 1 diabetes mellitus (T1DM). DM represents a collection of clinical, radiological, and histological findings on the breast. Case report 1: We report a 37-year-old woman, with T1DM diagnosis. The chief complaint included a 2-week history of an enlarging left breast lump. BI-RADS 4C was diagnosed in mastography. Pathology study showed DM. Case report 2: A 42-year-old woman with T1DM diagnosis noted an enlarging left breast mass. BI-RADS 4C lesion was diagnosed by mastography. DM was determined by pathology study. Literature review: The association between T1DM and $D M$ has been related to microvascular complications and is clinically indistinguishable from breast cancer. Breast ultrasound is the standard of choice for DM diagnosis. Pathogenesis of DM remains unknown. As a benign disease DM does not need surgery, only surveillance has been recommended. Conclusion: The DM should be considered in patients with microvascular complications of T1DM.
\end{abstract}

Key words: Diabetic mastopathy. Type 1 diabetes mellitus. BI-RADS 4C.

\section{Introduction}

Diabetic mastopathy (DM) is a rare, benign fibroinflammatory breast disease. Pathology studies have shown lymphocytic ductitis and lobulitis with varying degrees of fibrosis, vasculitis, epithelioid fibroblasts, and lymphoid nodule formation. Furthermore, named lymphocytic mastopathy, fibrotic mastopathy or sclerosing lymphocytic lobulitis, and DM have been associated with uncontrolled type 1 diabetes (T1DM) in premenopausal women², but cases with type 2 diabetes and male patient have been described too ${ }^{3}$. DM was initially described by Soler and Khardori ${ }^{1}$ and represents a collection of clinical, radiological and histological features found in breast lumps. In this review we describe two cases of DM that mimics breast cancer by clinical examination and radiological assessment.

\section{Case report}

\section{Case 1}

37-year-old woman, with a long history of T1DM, has been diagnosed with multiple diabetes-related complications such as chronic kidney disease, retinopathy, and hypertension. The chief complaint included a 2-week history of an enlarging left breast lump. Clinical examination showed a $5-\mathrm{cm}$ left breast nodule and no enlarged nodes where detected during axillary examination. Mastography and mammary ultrasound showed under the CC BY-NC-ND license (http://creativecommons.org/licenses/by-nc-nd/4.0/).
Available online: 17-10-2019 Rev Med Hosp Gen Mex. 2019;82(4):221-224 www.hospitalgeneral.mx er México SA de CV. This is an open access article 


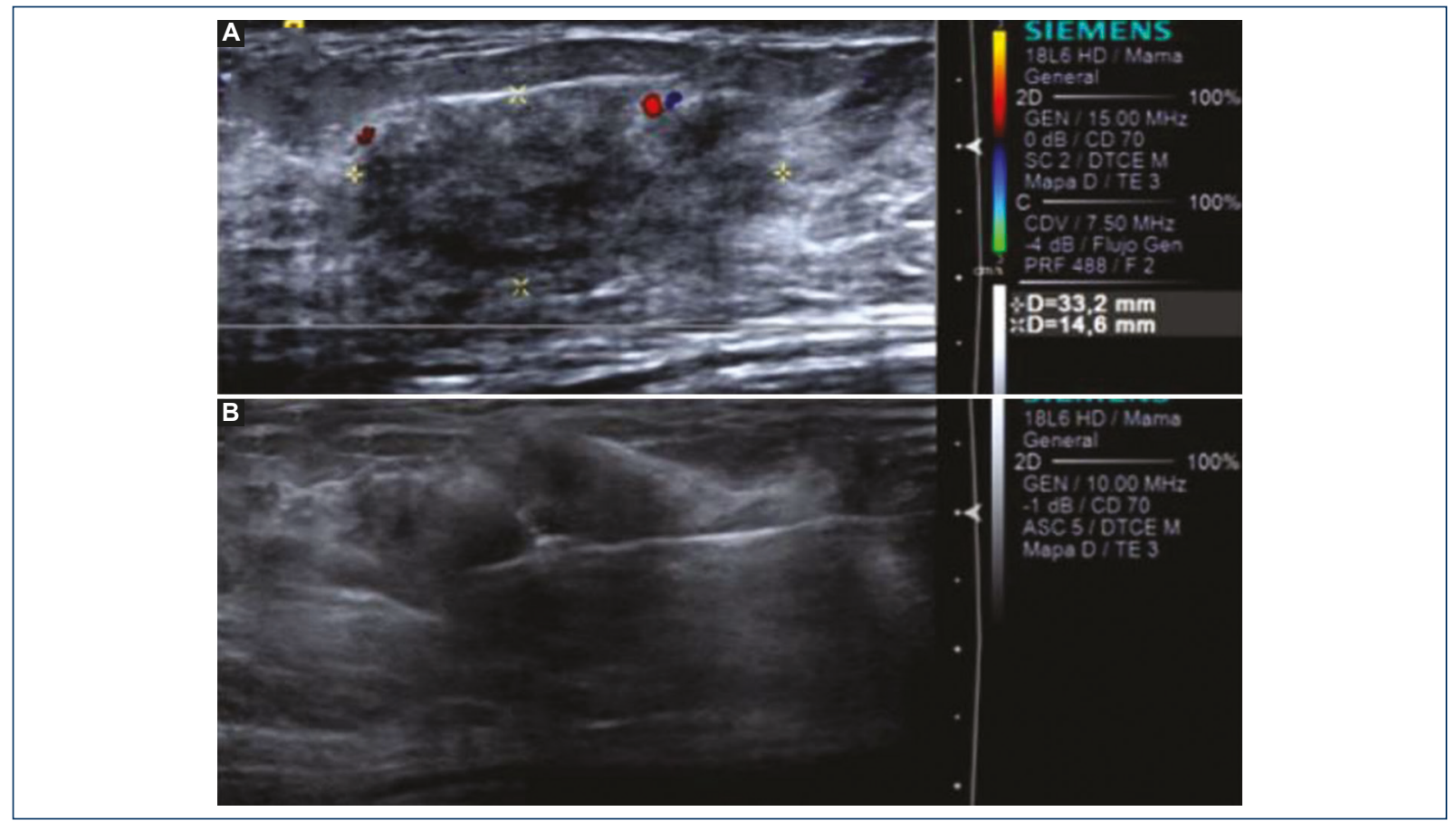

Figure 1. Breast ultrasound. A: irregular mass with angular margin and parallel orientation, show posterior shadowing. Color Doppler showing no vascular flow within the mass; B: percutaneous breast biopsy and the tip of the needle lie in the center of the lesion.

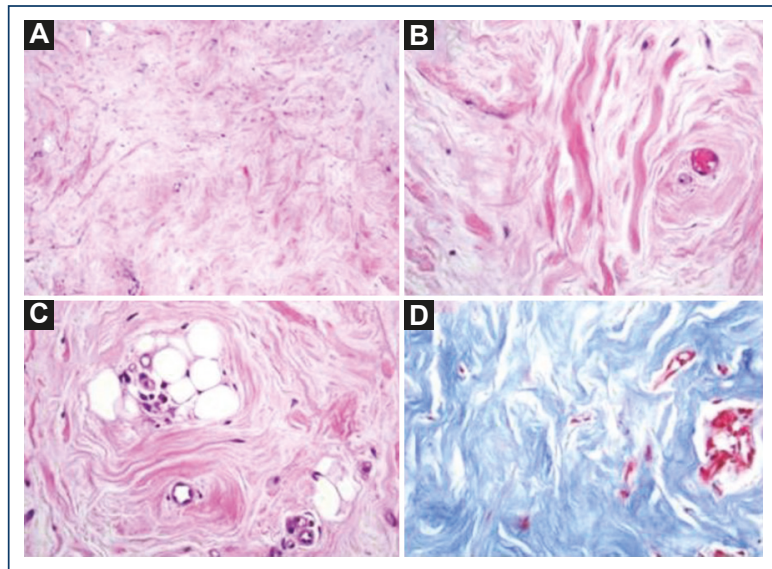

Figure 2. The characteristics lesions of diabetic mastopathy. A: hyalinized fibrous collagen bundles ( $H$ and $E, \times 100)$; $\mathbf{B}$ : approach of figure $\mathbf{A}$, thick bundles of collagen $(H$ and $E, \times 400) ; C$ : adipose tissue atrophy and lymphoplasmacytic inflammation foci are evident in some fields (green arrow) ( $\mathrm{H}$ and $\mathrm{E}, \times 400)$; D: the collagen bundles and fibrotic tissue are more evident with Masson's straining (Masson $\times 400$ ).

BI-RADS 4c (Fig. 1). Ultrasound-guided biopsy was performed, and pathology study showed DM without evidence of invasive carcinoma (Fig. 2).

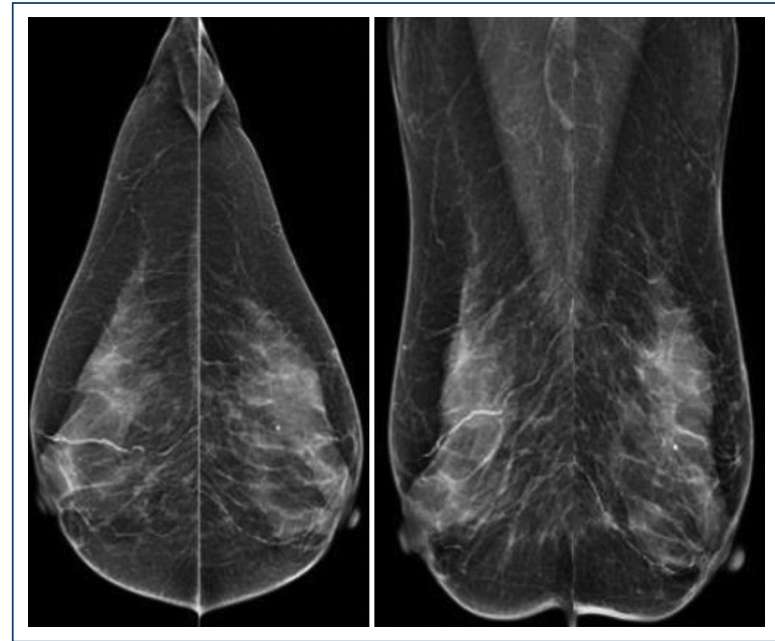

Figure 3. Mammography: the breast is heterogeneously dense; there is an oval mass with obscured margin at the upper outer quadrant in the left breast.

\section{Case 2}

We report a 42-year-old woman with a long history of T1D with diabetic neuropathy. She came to our center because of an enlarging left breast mass. Clinical examination showed a left breast mass with nipple 


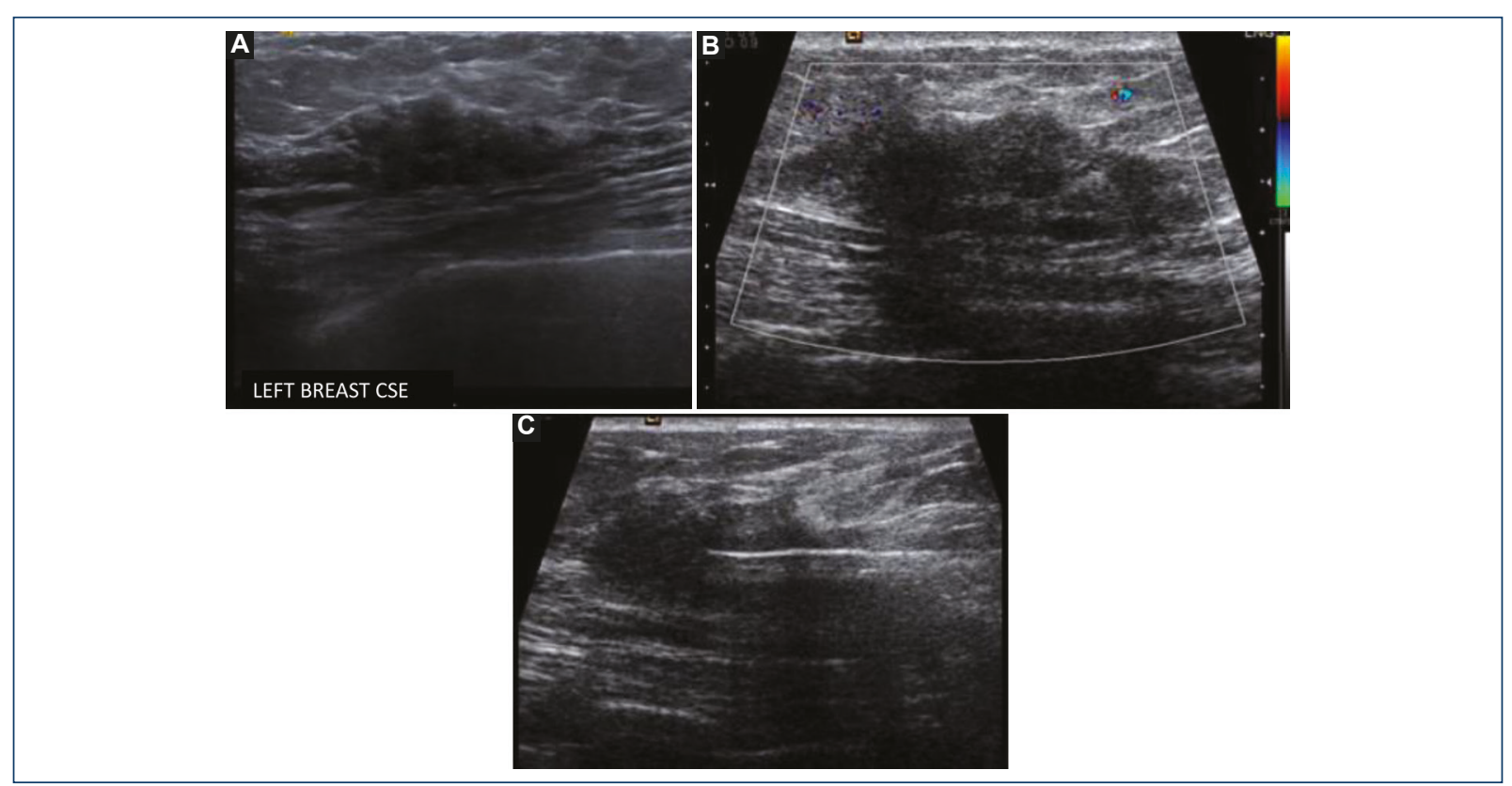

Figure 4. Diabetic Mastopathy. A, B: breast ultrasound: irregular mass with angular margin, posterior shadowing, and parallel orientation color Doppler showing no vascular flow within the mass; C: percutaneous breast biopsy.

retraction. Mastography and ultrasound revealed a left breast BI-RADS-4c lesion (Figs. 3 and 4). Ultrasound-guided biopsy was performed, and after pathology study, DM was diagnosed.

\section{Literature review}

Soler and Khardori ${ }^{1}$, in 1984, were the first to describe the association between diabetes mellitus and benign fibroinflammatory breast disease. Based on different reports, the association between diabetes mellitus and DM has been reaffirmed and associated with the presence of microvascular complications (nephropathy, retinopathy, or neuropathy $)^{6}$. It usually appears as a palpable and hard breast lump, clinically indistinguishable from breast cancer.

Mammography is usually the first study for evaluation in women with breast palpable nodule. The most common mastographic findings in DM are: (1) a breast nodule with high density and poorly defined margins, (2) focal asymmetry in density, without associated calcifications, speculated borders or changes of adjacent skin, and (3) normal axillar nodules s.9. $^{7}$.

Breast ultrasound is the standard of care imaging study for DM diagnosis. The most common findings include irregular hypoechoic breast lesion with indefinite, angulated or microlobulated margins, with acoustic shadow ${ }^{10}$. There is no ultrasound signal suggesting vascularity in Doppler mode. Normally, these findings do not rule out malignancy and a BI-RADS 4a is the most usual classification determined in these lesions. The ultrasound-guided core biopsy is better than the excisional biopsy. Surgical biopsy is not indicated for the diagnosis, only in cases of high uncertainty of malignancy; it is not recommended as initial therapy because a high percentage of recurrence is observed.

In 1987, Byrd and Hartmann described the histopathology features of DM as the combination of connective tissue overgrowth, and perivascular lymphocytic infiltrate as a characteristic of this lesion ${ }^{4}$.

The pathogenesis of DM remains unknown, several mechanisms have been suggested; Seidman et al. proposed that administration of insulin could produce chronic inflammation; Tomaszewski et al. described DM as an increased collagen production and decreased degradation related to the hyperglycemic state; and Ely et al. hypothesized that bilateral presentation and the multiple recurrences would indicate a systemic cause rather than a local event.

In a follow-up of 19 patients (including 17 women and 2 men) with DM, Ely et al. ${ }^{5}$ described the histopathologic findings of DM characterized by the presence of lymphocytic ductitis or lobulitis, and keloidal fibrosis and perivasculitis. They described the presence of ductitis as universal, but lobulitis was present only in female DM cases (as the men breast lacks lobules). Six of 19 cases recurred at follow-up (three ipsilateral, two contralateral, and one bilateral). In 2013, Akahori et al. ${ }^{3}$ described a case of DM in a man with 20 years of diagnosis of type 2 
diabetes treated with hypoglycemic agents. He had diabetic retinopathy and neuropathy, but no nephropathy.

MD can present with synchronic or metachronic lesions (multifocal). Surveillance is the only treatment for these patients, but any new breast mass needs a complete evaluation to rule out malignancy, which may represent multiple biopsies overtime ${ }^{10}$. The breast cancer prevalence in these women is similar than general population, but the diagnosis of malignancy is more difficult.

\section{Conclusion}

The DM represents an uncommon entity but should be considered in patients with microvascular complications of T1DM.

\section{Conflicts of interest}

The authors declare that they have no conflicts of interest.

\section{Ethical disclosures}

Protection of human and animal subjects. The authors declare that no experiments were performed on humans or animals for this study.
Confidentiality of data. The authors declare that they have followed the protocols of their work center on the publication of patient data.

Right to privacy and informed consent. The authors have obtained the written informed consent of the patients or subjects mentioned in the article. The corresponding author is in possession of this document.

\section{References}

1. Soler NG, Khardori R. Fibrous disease of the breast, thyroiditis and cheiroarthropathy in Type 1 diabetes mellitus. Lancet. 1984:1:193-5.

2. Neetu G, Pathmanathan R, Weng NK. Diabetic mastopathy: a case report and literature review. Case Rep Oncol. 2010;3:245-51.

3. Akahori H, Kaneko M, Kiyohara K, Terahata S, Sugimoto T. A rare case of diabetic mastopathy in a Japanese man with Type 2 diabetes mellitus. Intern Med. 2009;48:915-9.

4. Schwartz IS, Strauchen JA. Lymphocytic mastopathy: an autoimmune disease of the breast? Am J Clin Pathol. 1990;93:725-30.

5. Ely KA, Tse G, Simpson JF, Clarfeld R, Page DL. Diabetic mastopathy a clinicopathologic review. Am J Clin Pathol. 2000;113:541-5.

6. Cao MM, Hoyt AC, Bassett LW. Mammographic signs of systemic disease. RadioGraphics. 2011;31:1085-100.

7. Stavros AT, Rapp CL, Parker SH. Ecografía de Mama. Marbán. Madrid, España, 2006.

8. Sabaté JM, Clotet M, Gómez A, De Las Heras P, Torrubia S, Salinas T. Radiologic evaluation of uncommon inflammatory and reactive breast disorders. RadioGraphics. 2005;25:411-24.

9. Selmaa VR, Herreroa JC, Rubio CM, Muñoz RC, Noguera PJ, Navarro MF, et al. Mastopatía diabética: clínica, hallazgos radiológicos y anatomopatológicos y tratamiento. Radiología. 2011;53:349-54.

10. Aguilar VN, Fornas GM, Benavent RM, Alcazar JL, Llopis CA, Segarra TM, et al. Mastopatía Diabética: espectro De Hallazgos En Las Pruebas De Imagen. SERAM Sociedad Española De Radiología E Imagen. Presentación Electrónica Educativa; 2014 